\title{
Impasses e potencialidades de um filme assintagmático
}

\author{
Leonardo Gomes Esteves' \\ https://orcid.org/0000-0001-8540-2823 \\ I - Universidade Federal de Mato Grosso. \\ Cuiabá (MT), Brasil.
}

Resumo: Este artigo busca propor uma reflexão sobre o que é aqui chamado de filme assintagmático, tomando como contexto a produção cinematográfica em torno de Maio de 68. O objeto contemplado por este estudo de caso é o curta-metragem La révolution n'est qu'un début. Continuouns le combat (1968), de Pierre Clémenti. Para esta análise e para a compreensão do que se propõe conceitualmente, leva-se em consideração a emergência de um "estado selvagem" através da sobreimpressão imagética, como propõe Noguez (2010), e de um tempo subjetivo dela advinda, como prevê Clerget (2001). A formulação está em oposição ao estabelecido por Metz (2010) como sintagma no cinema.

Palavras-chave: cinema experimental; sobreimpressão; Pierre Clémenti; maio de 68.

\begin{abstract}
Impasses and potentialities of an assyntagmatic film - This article proposes a discussion over what is here established as an assyntagmatic film, targeting May 68's film production. La révolution n'est qu'un début. Continuouns le combat (1968), by Pierre Clémenti, is the focus of the present analysis. As for what is understood as an assyntagmatic film, we take into account the emergence of a "wild state" throught visual overprint, as established by Noguez (2010), and a subjective time, as proposed by Clerget (2001). It's an opposition to what is called a syntagm on cinema by Metz (2010).
\end{abstract}

Keywords: experimental cinema; overprint; Pierre Clémenti; may 68.

\section{Introdução}

Pierre Clémenti é ainda um jovem ator quando começa a desenvolver algumas experiências atrás das câmeras, realizando filmes experimentais, 
caracterizados por um expressivo montante de técnicas de sobreimpressão. O ano de 1968 é especialmente produtivo, trazendo à luz três obras. Entre elas, chama a atenção um longo título, composto por duas frases: La révolution n'est qu'un début. Continuons le combat. Em convergência com a verve político-militante do período, com a cultura das manifestações e os confrontos com a polícia, mas sem perder de vista a sintonia com o underground americano, o filme de Clémenti borda um panorama muito peculiar. Neste, a contestação repercute por um leque variado de temas que vai do privado ao público, ou do pessoal ao político; da militância local (o Maio de 68) aos temas internacionais ${ }^{1}$; das questões comuns ao cardápio de reivindicações estudantis às do mundo da arte.

La révolution se notabiliza também por constar, ele mesmo, em uma lacuna. Trata-se de um filme indisponível durante muito tempo, tendo emergido apenas no final dos anos 1990. Conforme nos informam as cartelas iniciais, produzidas a partir da digitalização do curta-metragem já neste século, $L a$ révolution teria ficado inédito, mantido sob a guarda do pintor Frédéric Pardo por mais de 25 anos. Membro do que se chamou "constelação Zanzibar", grupo ao qual Clémenti pertencia, Pardo o entregou a Sally Shafto, pesquisadora responsável pela pioneira prospecção sobre o grupo Zanzibar², e a partir daí, é colocado em circulação.

O presente artigo busca meditar sobre este curioso filme rodado nos entornos do Maio de 68, partindo, contudo, de algumas limitações. Não conhecendo

1 Ao citar "temas internacionais" estou considerando, por exemplo, a questão racial nos Estados Unidos. Clémenti filma uma fotografia de Dennis Brack tirada em julho de 1967, em Michigan, durante a revolta de Detroit. Nela se vê dois homens negros alvejados. Agradeço a Valérie Matteau, do Ryerson Image Centre, pelas informações sobre a foto; e a Mark Sealy pela mediação. Agradeço também a Dennis Brack pela confirmação dessas informações. Para a atualidade desta imagem em La révolution (publicada originalmente no ano anterior em Newsweek), há uma possível explicação: ela foi capa da revista italiana Panorama n 105, de 18.04.1968 - duas semanas após a morte de Martin Luther King. Se a origem da fonte procede, o enquadramento de Clémenti parece respaldá-la: se fecha sobre a foto de modo a não enquadrar o título do periódico e a manchete, "Il credo di Martin Luther King". Outro aspecto a ser apontando como tema internacional é o assassinato do senador Robert Kennedy, filmado por Clémenti enquanto manchete do jornal Paese sera e rememorado no filme pela data, 06 de junho, em letras pulsantes.

2 Os filmes Zanzibar são resultado de uma proposta bastante excêntrica. Disposta a investir dinheiro em um cinema de caráter experimental, a herdeira Sylvina Boissonnas passa a financiar a produção de filmes em 35mm (bitola identificada a propósitos comerciais). O faz, contudo, sem exigir documentos como roteiro, orçamento ou prestação de contas, dando total autonomia ao realizador. Neste cenário, destaca-se a filmografia de Serge Bard, ex-estudante sem nenhuma experiência prévia no cinema; o experimento em média-metragem do artista plástico Daniel Pommereulle, Vite (1969); o longa-metragem da então editora Jackie Raynal, Deux fois (1968); e a continuidade da filmografia de Philippe Garrel, representante do jeune cinéma francês em 1968. A produção filmográfica atribuída ao grupo Zanzibar está compreendida entre 1968-1970. Sobre o grupo ver Coelho (2013) e Shafto (2007). 
os demais títulos rodados por Clémenti em 1968, não visionados por este pesquisador até a escrita deste artigo ${ }^{3}$, a análise estreita o debate no que concerne à conversação entre o curta e os demais títulos do diretor. Interessa, portanto, pensá-lo não prioritariamente alocado dentro de uma filmografia autoral, mas desgarrado dela e se aproximando dos eventos externos que contagiam o discurso do filme, tornando-o, então, atualíssimo - sobretudo no que concerne ao descaso quanto à questão da autoria. Dessa maneira, propõe-se pensar, por meio deste artigo, em impasses e potencialidades contidas a partir da análise das imagens de La révolution. Tais impasses e potencialidades estariam centrados no que se chamará aqui de assintagmático; ou seja, diverso da ideia de uma construção sintagmática, tomando como referência a concepção de sintagma no cinema trabalhada por Metz (2010) em matiz estruturalista e as definições de sobreimpressão propostas por Clerget (2001). Tais características do assintagmático irão ecoar uma nova sensibilidade, alinhada ao que Lyotard irá propor, mais tarde, como a-cinema. Compreende-se, entretanto, que o filme assintagmático deverá repercutir essa nova sensibilidade para além da técnica (sobreimpressão), incorporando-a ao discurso e o tornando um amálgama pluridimensional que está, em última análise, decretando o fim da arte e a morte do autor.

A partir da ideia de um filme assintagmático, a reflexão buscará interpretá-lo tomando como ponto de fuga a paisagem de 68, da verborragia ao esvaziamento. Neste exercício de aproximações e dissociações, ganha fôlego o recurso mais utilizado por Clémenti (amplamente empregado por ele em outros filmes), a sobreimpressão — tida por Noguez (2010) como um propulsor para estimular um “estado selvagem". Será preciso contextualizá-la em uma discussão pautada pela ideia de desconstrução do cinema, em voga à época, tomando como referência o discurso das vanguardas e o trabalho de Étienne O'Leary, realizador underground próximo a Clémenti.

\section{Sobre a natureza das imagens de La révolution}

La révolution n'est qu'un début. Continuons le combat (1968) é rodado em $16 \mathrm{~mm}$, uma bitola largamente empregada pelo cinema experimental e militante. Caracteriza-se por uma maior facilidade (o rolo é menor, mais leve), mas também por uma menor definição (objetos mais distanciados da lente

3 Durante o ano de 1968, Clémenti realiza também Livret de famille e Souvenirs souvenirs. Padellec (2007) observa que Livret de famille e Art de vie (1969) aparecerão "fusionados" em Visa de censure $n^{\circ}$ X(1976), obra à qual esta pesquisa teve acesso. 
tendem a ficar mais granulados e, portanto, menos nítidos). O negativo empregado no curta-metragem em questão é reversível, o que implica em um contraste maior entre as cores, favorecendo efeitos de coloração ${ }^{4}$.

Para Clémenti, o 16mm (como o Super-8) tem também um sentido doméstico de fabricação de imagens que servirá como um ponto de partida libertador para se desassociar de um cinema industrial, ilusionista 5 . A virada se daria justamente na utilização rotineira da câmera. La révolution não faz outra coisa senão encaminhar a produção de imagens para um aspecto personalíssimo de captar a rotina. O curta resulta de filmagens efetuadas entre Roma e Paris durante maio e junho, enquanto Clémenti filma Partner (1968) com Bertolucci na Itália e participa das manifestações na França.

As primeiras sequências de La révolution ensaiam potencialidades de texturas a partir de sobreimpressões e colorações sobre imagens da esposa de Clémenti, Margareth. São tomadas que trabalham sobre abstrações, imprimindo movimentos variados com luzes nuançadas, desfoques, velocidades de câmera divergentes.

Alguns desses planos íntimos, familiares, são intercalados por uma série de takes ligeiros sobre paisagens e ruínas. A partir desse trecho, mas também de muitos outros ao longo do filme, pode-se discorrer sobre a encenação permanente de um jogo de distâncias. As distâncias da câmera parecem, por exemplo, demarcar as distâncias entre uma instância subjetiva e outra objetiva, que oscilam entre imagens abstratas, disformes, e outras figurativas, proporcionando imbricações entre elas. Desta forma de estabelecer ligações orgânicas, distribuídas em camadas, entre aspectos conflitantes, ou distantes, se dá também o cruzamento entre o público e o privado. Shafto (2007, p. 135) atribui a mistura entre o público e o privado no filme de Clémenti a uma espécie de "ilustração involuntária" para um dos motes do feminismo americano cunhado por Carol Hanisch em 1969, "The personal is political"I "o pessoal é político".

\footnotetext{
4 As informações sobre a bitola e qualidade do negativo (reversível) de La révolution são dadas por Padellec (2007); Shato (2007); e pela Cinémathèque française. Disponível em: <https://www.cinematheque.fr/film/102556.html>. Acesso em: 29 fev. 2020.

5 Tomo como referência para este argumento dois depoimentos dados por Clémenti, extraídos de um debate com outros cineastas (Glauber Rocha, Jean-Marie Straub e Miklos Jancsó) em 1970: "Quando as pessoas descobrirem o cinema, mudarão ao criar seus próprios cinemas"; e "Quando as pessoas veem um filme, experimentam um tipo de identificação e saem do cinema sob forte influência da estrela do filme. Eu acho que quando as pessoas começarem a filmar com suas próprias cameras, quando as apontarem para suas famílias, seus lares, seus trabalhos, algo vai provocar um estalo em suas cabeças, porque eles vão descobrir que não é daquela forma nos filmes" (HARTOG, 2004, tradução nossa). Agradeço a Vinícius Mazeti por me apontar esse material republicado na internet.
} 
O que está mais nítido até aqui (na contínua renúncia da nitidez) é o gesto de manipular o visual. De compor uma imagem que nunca é apenas uma, mas proposta em diversas camadas que estão em movimento entre si e são parcialmente nítidas. As sobreimpressões têm em La révolution um papel fundamental no mecanismo de manipulação do visível. A utilização do recurso aporta também outras questões. Para Dominique Noguez (2010), as sobreimpressões fariam a ponte entre a vanguarda francesa dos anos 1920 e o New american cinema dos anos 1960, rompendo com o caráter icônico da imagem. O fim estético da sobreimpressão, para o autor, acabaria por transmitir à percepção um “estado selvagem" (NOGUEZ, 2010, p. 34).

Levar a percepção a um "estado selvagem" poderia corresponder a um estágio de liberdade que rompa, sobretudo, com as amarras da (história da) arte. Mas, também, do cinema e, por que não?, de um cinema militante contemporâneo ao Maio de 68. Neste, vê-se delinear uma proposta tão interessada em politizar o discurso enquanto uma frente coletiva quanto em arrefecer individualidades e aspectos domésticos, rotineiros ou mesmo apolíticos - o que tampouco é uma tarefa fácil se for levada em consideração a politização excessiva que irá gerar afirmações como "tudo é político". O fato é que, entre o que se chamou de cinema militante e possui nele uma vasta identificação com a causa operária, com o postulado marxista-leninista encampado pela teoria crítica e com o tema da luta de classes, La révolution é um corpo estranho. Faz pontes improváveis.

A aproximação à pop art e à psicodelia é um dado explícito e problemático no filme de Clémenti. O parentesco com o New American cinema não é desprezível e repercute uma discussão de maior envergadura, que pode resvalar na pintura francesa contemporânea, acusando dessemelhanças. Isto é, no trabalho dos pintores da Nouvelle figuration/ Figuration narrative, que se verão incumbidos de trabalhar a partir de temas políticos. Esta geração vai conversar com o cinema em seus quadros em uma tentativa de se distanciar da influência americana, na qual as concordâncias plásticas teriam desencadeado a necessidade de demarcar uma figuração europeia, que buscaria superar tal semelhança. A justaposição/ sobreposição de quadros será um artifício característico para demarcar a distância de uma imagem única: "la Figuration cherche à échapper à l'autonomie de la seule image qu'elle propose dès lors comme l'extrait d'um film hors-champ" (GOUMARRE, 2008, 
p. 205). Nem tão distante disso está La révolution. A sobreimpressão excessiva de Clémenti o insere em um debate artístico que não é habitual na prática cinematográfica tida por militante, mas que está impregnado por uma influência warholiana7 e transita por tendências não restritas apenas ao cinema. Clémenti, entretanto, não nega a influência americana, como o quer a Nouvelle figuration. Ao contrário, se lamenta pelo fato de a Europa não tê-la supostamente absorvido ${ }^{8}$.

Voltando à composição visual e multíplice de La révolution, após os planos em torno de Margareth segue-se um segundo bloco de imagens, no qual o que está ao alcance das insinuações discursivas é o Maio de 68. Às tomadas de rua são adicionados componentes textuais. Tal como na pesquisa de linguagem das imagens, as letras se movem, pulsam em cores e fontes variadas, se aproximam e se distanciam. Repercutem um apelo pop incomum à seara militante. Logo nas primeiras tomadas feitas à rua, uma fusão irrompe sobre a imagem escura e fria de um núcleo policial. Um estrato claro, de temperatura quente, avermelhada, de Margareth caminhando com o filho do casal, Balthazar, se choca contra o registro dos policiais. É uma sobreimpressão passageira, outra forma de trabalhar distâncias entre o que é íntimo, confortável, e o que é estranho, repulsivo ${ }^{9}$. La révolution não perde de vista o tema do confronto às autoridades.

Os demais blocos do curta-metragem aprofundam as sobreimpressões e o jogo oscilante de distâncias. Há o exercício de mesclar materiais estáticos e em movimento - entre as fotografias de um homem negro americano ensanguentado (autoria de Dennis Brack) e de um ferido no Maio francês ${ }^{10}$, e as imagens em movimento de Balthazar e a mãe. Há a sucessão de inscrições com palavras de ordem, expressões e menções ao movimento 22 de

7 Influência que estaria marcada, sobretudo, por Chelsea girls (1966), no qual Warhol e Paul Morrisey exploram filtros e colorações em uma tela composta sempre por dois planos. Importante observar que o resultado visado por Clémenti irá radicalizar essa proposta, tanto no que concerne ao uso de colorações quanto à própria ideia de fabricar uma imagem que não é composta por apenas uma unidade.

8 Torno a me servir dos depoimentos do ator/realizador no debate sobre cinema político com Glauber, Straub e Jancsó: "As ações revolucionárias de toda uma geração americana, a juventude, derrubaram um sistema que era uma das maiores forças do país. Se as pessoas foram capazes de derrubar esse sistema, significa que foi algo positivo. Enquanto na Europa, nada acontece"; e "Eu sinto que uma geração americana nos deixou uma herança, e seria estúpido não lucrar com isso..." (HARTOG, 2004, tradução nossa).

9 É preciso observar que o filme se coloca contra a polícia, como se faz ler uma das frases que despontam fragmentadas sobre imagens: "A polícia do poder mata, viola, castra a liberdade" (tradução nossa).

10 Não foi possível localizar a autoria da fotografia utilizada por Clémenti. Afirmo se tratar de um "ferido no Maio francês" porque localizei outra fotografia do mesmo ferido, mas de outro ângulo. A imagem, de 06 de maio de 1968, pertence ao arquivo da Prefeitura da Polícia de Paris. É possível vê-la em: <https://www.polkamagazine.com/mai-68-photographie-par-la-police-de-lautre-cote-des-barricades/>. Acesso em 29 fev. 2020. 
março e à data do assassinato de Robert Kennedy ${ }^{11}$. Os registros passam em seguida para o entorno pessoal. Imagens de amigos e integrantes da "constelação Zanzibar"12 distanciam o filme da atmosfera militante e estreitam o abismo entre política e curtição.

O filme encerra sua verborragia visual - discurso apoiado sobre imagens excessivas, tematicamente dúbias e sem complementos sonoros - acompanhando o registro de uma perambulação descalça. Nela, pisa-se em imagens fusionadas (estas, também em movimento). No percurso, surgem, em fragmentos, frases decisivas que formalizam o descarte absoluto: “A arte é uma merda. Este filme é uma merda. Aquele que o fez é um idiota. Aqueles que o discutem são idiotas, e viva a expressão livre" (tradução nossa). Nas tomadas finais se vê a fusão entre o abrir e fechar de uma mão, a insurgência das expressões "poder à imaginação" e "revolução permanente", e finalmente a imagem de Clémenti. Ele surge com uma venda nos olhos, como que tateando um sentido - a expressão livre? Um "estado selvagem"? Pode-se discorrer aqui sobre uma ilustração à busca da libertação do conceito de arte; sobre a rejeição à seriedade do autor; e mesmo a liberação das amarras conceituais que buscariam discuti-lo enquanto filme.

O discurso niilista que acomete a própria obra ao final resume o percurso de uma manifestação difusa, que submeteu os aparatos estéticos à praxis vital - e aí se torna efetivamente político, de vanguarda. O Maio de 68 em si, as palavras de ordem, as imagens dos confrontos, são apenas fragmentos incoporados a uma nova sensibilidade que já não prevê demarcações nítidas entre um estado lúcido/translúcido e outro alucinógeno. Tais fragmentos parecem melhor contextualizados do que as fotografias enxertadas de forma a fazer pulsar um conteúdo político de menor consistência. Mas eles tampouco sustentam um discurso de reparação da sociedade, como visado com fôlego à época. O filme não engendra uma reflexão exclusiva sobre as manifestações, ele se reporta a ela, torna-a repertoriável. Clémenti trata o Maio de 68 como (mais) uma ocorrência do cotidiano - tal como encontrar amigos, trabalhar, filmar a família e a $\mathrm{si}^{13}$. La révolution parece representar um espaço híbrido de intersecção entre home-movie, filme-diário e filme

11 A associação à morte de Kennedy ("6 juin 68") é apontada por Shafto (2007, p. 135).

12 Frédéric Pardo, Tina Aumont, Caroline de Bendern, assim como a banda Les Fabuleux Loukoums e outros.

13 Sobre a obra de Clémenti, Bassan (2014, p. 77) aponta a tendência de ir e vir entre o íntimo e as críticas e reivindicações sociais por meio das trucagens ópticas, efeitos de íris. Para ele, La révolution soa como um ciné-tract. 
militante. O impasse entre essas expressões, que oscilam entre o desejo de introspecção e a paradoxal inquietação de integrar-se ao meio externo, exemplificam um viés virtual. Cogita potencialidades sem, contudo, se apegar a uma identidade demarcada.

De uma forma muito pessoal, textos e imagens partilham de uma identidade inconstante, aleatória e fragmentária. La révolution é uma referência consistente para uma parcela de filmes que vai se relacionar com o Maio de 68 a partir de uma certa distância, na qual a militância se dá com maior ênfase no discurso que ambiciona a desestruturação da arte. É o refinamento, ou talvez embrutecimento, pela via estética - e um arrefecimento das questões habituais que tomam corpo na produção militante em torno de 68 - que vai caracterizar o trabalho do grupo Zanzibar, para o qual La révolution converge.

\section{O assintagmático a partir da sobreimpressão}

Ao falar em sintagma no cinema, Metz (2010) está invariavelmente falando em narrativa. E o processo narrativo - que, em sua defesa, ocupa grande parte da produção cinematográfica - exerce, portanto, um protagonismo na forma de estudar procedimentos linguísticos nas imagens em movimento. Ao se ocupar das expressões não narrativas, mesmo uma "semiologia autônoma", restrita a segmentos marginais, seria ainda devedora dos '"verdadeiros' filmes" ${ }^{\prime 14}$. Dentro dessa linha, há no pioneiro A significação no cinema - obra que registra a incursão do cinema nos estudos estruturalistas e cuja aparição é contemporânea à obra de Clémenti aqui analisada - um raciocínio bem objetivo que visa a estabelecer correspondências entre o plano e a frase.

Mais do que pela quantidade de significação (noção muito difícil de usar, ainda mais no cinema) a imagem é 'frase' pelo seu estatuto assertivo. A imagem é sempre atualizada. Assim é que até as imagens - o que é bastante raro, aliás - que corresponderiam pelo conteúdo a uma palavra, ainda são frases: é um caso particular, particularmente esclarecedor. Um primeiríssimo plano de revólver não significa 'revólver' (unidade léxica puramente virtual), mas significa no mínimo, e sem falar das conotações, 'Eis um revólver'. Ele carrega consigo uma espécie de eis [...] Mesmo quando o plano é uma 'palavra', ainda é uma

14 "Nada indica que uma semiologia autônoma nos diversos gêneros não narrativos seja possível senão como uma série de anotações descontínuas assinalando as diferenças em relação aos filmes 'habituais'"' (METZ, 2010, p. 113, grifos do autor). 
palavra-frase, como em algumas línguas. (METZ, 2010, p. 84-85, grifos do autor).

Desta forma, um discurso poderia, por exemplo, ser composto por um "sintagma linguístico maior que a frase e formado por várias frases, conjunto 'transfrásico'" (Ibidem, p. 39); a sequência, um grande conjunto sintagmático; e o plano, "a menor unidade da cadeia fílmica" (ibidem, p. 85). Metz irá propor, nos termos de um "sintagma alternante", uma reflexão em torno do que se convencionou chamar de montagem paralela, articulando finalidades distintas.

No que concerne às práticas que envolvem efeitos entre imagens, sendo a fusão, ou sobreimpressão, um deles, Metz os relaciona, assim como o faz com o plano, à ideia de "segmento mínimo". Elementos visuais, nunca fotográficos, as sobreimpressões são imagens, entretanto, menores, sem ligação com a realidade:

Estes recursos são um pouco para as tomadas o que os morfemas são para os lexemas; conforme o contexto, têm duas grandes funções: 'trucagem' (neste caso, trata-se de uma espécie de expoentes semiológicos que incidem sobre as imagens contíguas), ou 'pontuação' (METZ, 2010, p. 128).

A partir desses dados iniciais, como pensar a ideia de sintagma e a sobreimpressão enquanto elemento definidor em La révolution?

Primeiramente, seria importante observar que a ideia de discurso, sequência e plano, da forma como estabelecida por Metz, parece inadequada aqui. E que a sobreimpressão - seja ela feita na câmera, com um poder de manipulação bem limitado e entregue a um certo acaso, quanto na pós-produção, aí já plenamente controlável - assume um protagonismo que dificulta muito a tipificação de "segmento mínimo". Ao contrário, ela é um elemento elaborado ao máximo. Não se poderia tampouco considerar o uso excessivo de sobreimpressões por Clémenti enquanto uma função de "pontuação". "Trucagem" a rigor seria mais adequado, mas é uma função igualmente problemática se considerada enquanto um expoente semiológico que incide sobre as imagens contíguas, como propõe Metz. A ideia de contiguidade entre imagens em La révolution não se dá na lógica do "uma após a outra", mas do "uma dentro da outra". A simultaneidade que enfraquece a estrutura sucessiva, sintagmática, acarreta uma virtualidade rica em potencialidades. 
É, portanto, a sobreimpressão que viabiliza o projeto de produzir uma imagem que se reporta a uma realidade que é orgânica ao processo e não ao que a câmera se limita a captar enquanto profílmico. Esta outra realidade, sensível à manipulação e ao potencial criativo, acaba por restringir a realidade externa (seja ela qual for) a apenas um material à disposição da técnica e ao fluxo de criação. A imagem é discurso, "conjunto 'transfrásico"' que repele a natureza sintagmática e se dota de uma propensão a se fazer insinuar e nem tanto afirmar - aproximando-se do que Bassan (2001, p. 357), a partir da questão da velocidade no experimental, caracteriza como "a-cinema": hesitação a integrar um ou outro campo e, portanto, assumir uma ou outra identidade. Para a compreensão do termo "a-cinema", ou "acinema", e, sobretudo, sua associação à ideia de movimento/velocidade, como propõe Bassan, o texto "O acinema", de Jean-François Lyotard, publicado originalmente em 1973, é obrigatório.

O comentário de Bassan, inscrito na questão da velocidade enquanto oposição à montagem funcional, é respaldado por este trecho em Lyotard (2005, p. 227-228): "[...] o acinema se situaria nos dois polos do cinema tomado como grafia dos movimentos: a imobilização e a mobilização extremas [...] um no qual a imobilidade aparece: o 'quadro-vivo'; o outro, em que a agitação se manifesta: a abstração lírica". Ainda no artigo, Lyotard tratará a abstração no cinema em paralelo com a pintura abstrata, sem, contudo, abordar a sobreimpressão como elemento, mas considerando as "formas realmente ativas do cinema experimental ou underground" (Ibidem, p. 222).

Na extensão do experimental, Clerget (2001) redimensiona o papel da sobreimpressão, se aproximando dos resultados que tomam corpo nas propostas mais ambiciosas, como a de Clémenti. Nesta análise, algumas características se impõem, como a incompletude e a subjetividade, indo ao encontro do "a-cinema".

\footnotetext{
Uma imagem se impressiona sobre outra: duas imagens associadas em sobreimpressão dão origem a uma terceira imagem (ou três imagens a uma quarta, etc.), nascida do sentido de reencontro, de uma dissolução e de uma reforma, da confrontação entre dois motivos e sujeitos que pertencem ao mesmo espaço-tempo, mas foram fixados sobre o mesmo suporte. Mas a terceira imagem não é a soma de duas outras; representando, ao contrário, o trabalho do tempo sobre a memória, ela é incompleta pois é vítima de uma interatividade devorante, e se tornaria então uma representação da percepção de
} 
uma imagem passada mais ao filtro da memória do que à imagem mesmo. Uma fusão acorrentada que sobrepõe dois planos a dois instantes de suas durações, um fim e um início, criou uma certa temporalidade que encontra sua origem no primeiro plano e se prolonga ao próximo. A sobreimpressão evacua a temporalidade, mas atualiza um certo sentimento do tempo que nasce do cruzamento de duas temporalidades que se anulam. A sobreimpressão seria, então, a anulação do tempo objetivo em favor de sua percepção necessariamente subjetiva (CLERGET, 2001, p. 564, tradução nossa).

Tais palavras habilitam uma nova remissão a Lyotard no que concerne à definição de seu oposto, isto é, de uma imagem identificável. A oposição, atrelada ao cinema comercial, cabe neste comentário: "A imagem é representativa porque é reconhecível, dirige-se à memória do olho, a referências fixadas de identificação por serem 'bem conhecidas', estabelecidas. Essas referências são a identidade que mede o retorno e o lucro dos movimentos" (LYOTARD, 2005, p. 224, grifos do autor). No caso de La révolution, e a partir da sobreimpressão, trata-se de fabricar uma imagem subjetiva, descolada da "memória do olho"; ou, como propõe Clerget, uma imagem incompleta, fruto de uma dissolução e de uma reforma.

Pensando em termos imagéticos e tomando Metz como uma referência a ser superada, a imagem está propensa a quase nunca ser frase neste filme de Clémenti. O que talvez soe como uma grande ironia e vocação já na "menor unidade da cadeia fílmica" (o plano) para justificar o impasse que se manifesta em diversas chaves no curta. A ironia já se dá no título. Afinal, $L a$ révolution n'est qu'un début. Continuons le combat é composto por dois sintagmas, frases que não estão fusionadas, mas justapostas. Enunciam uma clareza, concisão e organização não assumidas pelo filme e sua propensão ao desapego - pelo discurso, pelo alvo da manifestação (de que revolução está, afinal, se falando?), pelo próprio trabalho entregue pelo filme.

É sobre uma "expressão livre" (Clémenti), a partir de um "estado selvagem" (NOGUEZ, 2010), que La révolution engrena seu jogo excessivo de sobreimpressões. É de fato sobre a anulação do tempo objetivo que a natureza "transfrásica" das imagens construídas, seja dentro da câmera ou já em uma mesa de trucagem, se manifesta voluntariamente. Um filme assintagmático não poderá ser visto fora do apego pela virtualidade, por não transmitir um enunciado acabado, mas incompleto, oscilante, instável, repleto de ironias. Apresenta o desprendimento pelas convenções em sua expressão visual e 
o verá replicado no tecido discursivo. Exprime o impasse alimentado pelas potencialidades que propõe em múltiplas arestas, mas que nunca chegam a consolidar um movimento uniforme. Discorrer sobre a ideia de um filme assintagmático, tomando La révolution como um paradigma imediato e restringindo o conceito aos entornos de 68, prevê examinar um estágio de contestação que reverbera a confusão discursiva característica do período.

É, ao fim, sobrepor movimento e inércia. O filme assintagmático está alinhado ao "a-cinema" no que concerne à adoção de uma postura pirotécnica (estética e discursiva) caracterizada pelo paradoxal excesso de movimento/inércia. Para o "a-cinema", escreve Lyotard (2005, p. 222): “[...] o cinema cessa de ser insensivelmente uma força de ordem: ele passa a produzir verdadeiros, quer dizer vãos, simulacros, intensidades gozosas, em vez de objetos consumíveis-produtivos". O assintagmático, enquanto expressão que incorpora um "estado selvagem" para além da conotação técnica (sobreimpressão), poderá ser aí interpretado como em conexão com as "intensidades gozosas". Nesse programa, compreende-se o gozo tal como trazido por Lyotard, a partir de Freud, Adorno e Klossowski: "desordem das pulsões", "composto das decomposições" (Ibidem, p. 222).

\section{O "estado selvagem" da escrita introspectiva}

A influência talvez mais contundente para o trabalho de Clémenti está na produção de Étienne O'Leary, cineasta ativo entre 1966-1968. Dentre a curta, mas radical filmografia de O'Leary, Homéo (1967) é o trabalho que mais se aproxima do que será desenvolvido por Clémenti - que junto a sua esposa e Olivier Mosset, outro membro da "constelação Zanzibar", figura frente à lente de O'Leary.

Homéo é, como sugere o nome, um esforço que se encarrega do registro de aspectos domésticos, um filme-diário psicodélico. Difícil pensar na sobreimpressão aqui também como "segmento mínimo", destacado da realidade, mas como fundador de um tempo subjetivo. Para O'Leary (2001, p. 279, tradução nossa), "Homéo é uma construção mental a partir da realidade visual, assim como a música em relação à realidade auditiva". O processo interno se sobrepuja à realidade, ou ainda, a arte ultrapassa a vida no que ela tem de mais banal. A inversão, ou desejo de se colocar contra a narrativa, fortalece o argumento de Metz acima, que estaciona as expressões marginais enquanto manifestações que orbitam em torno do cinema narrativo. É o que se vê na defesa de O'Leary: 


\begin{abstract}
É para mim a pesquisa de uma linguagem cinematográfica autônoma que não deve nada à narrativa comum senão tudo. O cinema, antes de tudo, faz parte de uma maneira de vida que se afirmará cada vez mais ao longo dos anos e do século a vir. Nós fazemos parte dessa mudança, e é por isso que eu procurei estabelecer em Homéo uma cadeia de mudanças perpétuas em uma constante evolução ou regressão que procura, antes de tudo, fazer um ponto. Eu poderia explicar minhas intenções mais diretamente, mesmo coladas à imagem, mas sei que as pessoas não iriam reter a ideia, mas a palavra; então, com medo de soar falso em relação a sua expressão real, eu me calo (O'LEARY, 2001, p. 279, tradução nossa).
\end{abstract}

Em seu discurso, as imagens não são suficientes, ou talvez não consigam transmitir uma ideia. É possível que tenham se tornado inaptas a comunicar algo ou que tenham perdido a potência frente à objetividade textual, como alega. Clémenti parece ter sido especialmente sensível a esse impasse exposto por O'Leary ao trazer para seu mosaico impreciso de vivências sobrepostas um extenso repertório de propensões textuais em texturas e direções diversificadas. O que, por outro lado, vai manifestar outro impasse.

Homéo é bem resolvido no que concerne a limitar seus procedimentos e ambições à construção mental que quer apenas pesquisar uma linguagem autônoma, como defende seu autor. Ele se mantém de certa forma fechado sobre si. Em um dado momento, filma o que parece ser um desfile militar sem de fato interferir criticamente sobre ele ou abarcar comentários, juízo de valores, amparados por uma vontade de se inserir sobre o contexto (externo) em que coexiste. La révolution não é indiferente ao que acontece em seu entorno. Toma partidos, absorve tendências, repercute o zeitgeist em chaves variadas. Parece articular um encontro incomum entre alucinação e militância, ou uma curiosa sobreimpressão entre arte pop e cinema de guerrilha.

Se há um "estado selvagem", para além da questão de problematizar uma natureza icônica da imagem, como o aponta Noguez (2010), ele se manifesta em La révolution como uma coleção de impasses e potencialidades. Resolve-se em uma indefinição permanente que, no final das contas, faz o filme ser imediatamente arquivado e resgatado bem mais tarde.

\title{
Conclusão: o assintagmático, sintoma do esvaziamento
}

É sem dúvida evidente que Clémenti e O'Leary tenham buscado aperfeiçoar, também a partir da sobreimpressão, um editorial comum que estivesse 
disposto a levar o cinema para um âmbito pessoal e desmistificador. Homéo é anterior ao Maio de 68 e é difícil imaginá-lo tão distante de La révolution se tivesse sido rodado mais à frente. Chromo sud (1968), por outro lado, vai permanecer pouco afeito à politização que não escapa do diário manipulado de Clémenti, o que pode corroborar os argumentos que apontam a inconsistência da encorpada militante por este cinema.

Se a sobreimpressão pôde ser associada a um "estado selvagem" no cinema em torno de 68, não se pode passar por ela (e por ele) sem abordar esses cineastas e, especialmente, o encontro atípico e pouco promissor com a militância que irá resultar em La révolution. É talvez nesse flerte passageiro e um tanto sem convicção que irá transparecer um impasse maior, a figuração de um vazio, da falta de perspectiva que irá culminar no descarte total. O Clémenti que ao final de La révolution anda às cegas, pisando em imagens (a essa altura já tão descartáveis e insignificantes em suas camadas e configurações "transfrásicas", bombardeadas por complementos textuais), parece não saber o que, afinal, dizer. E também o que fazer com o filme —-senão confiá-lo a alguém que irá armazená-lo por décadas.

A ideia de um filme assintagmático quer repercutir esse "estado selvagem" enquanto expressão de um esvaziamento total. É amparada pela formulação de frases sobrepostas que não expressem uma coisa, mas várias, moventes, em vias de reconfigurar a intenção. O sintagma, enquanto plano cinematográfico, perde sentido. O esvaziamento parte das imagens para caracterizar o discurso, inconstante, incapaz de se apegar a algo que permanecerá inalterado. Não se trata, contudo, de regredir a um estado bárbaro, mas de fazer aflorar um estado emocional, instável, interno e imprevisível, como o pensamento. É, em última análise, denegar a instituição cinema, sua finalidade industrial; ou seja, esvaziá-la em seu propósito vitalício de fomentar, quer produtos para o entretenimento, quer para o mercado de arte. É, também, uma forma de discorrer sobre o que será mais tarde caracterizado como "a-cinema".

Leonardo Gomes Esteves é professor da Universidade Federal de Mato Grosso e doutor em Comunicação Social pela PUC-Rio.

leonardogesteves@gmail.com 


\section{Referências}

BASSAN, R. Cinéma expérimental. Abécédaire pour une contre-culture. Crisnée: Yellow Now, 2014.

Lexique formel, historique et affectif des années 60-90. In: LEBRAT, C; BRENEZ, N.

(Orgs). Jeune dure et pure! Paris: Cinémathèque Française, 2001.

CLERGET, S. Support fragile, forte impression (la surimpression dans Fragiles mémoires d'Olivier Fouchard). In: LEBRAT, C; BRENEZ, N. (Orgs). Jeune dure et pure! Paris: Cinémathèque Française, 2001.

COELHO, R. (Org.). Os filmes Zanzibar: dândis de Maio de 68. Rio de Janeiro: Caixa Cultural, 2013.

ESTEVES, L. G. Dialéticas da desconstrução: Maio de 68 e o cinema. 2017. 293 f. Tese (Doutorado em Comunicação Social) - Pontifícia Universidade Católica do Rio de Janeiro, Rio de Janeiro, 2017.

GOUMARRE, L. Figurer la revolution. In: BAECQUE, A.; BOUQUET, S.; BURDEAU, E. Cinéma 68. Paris: Cahiers du cinéma, 2008.

HARTOG, S. There's nothing more international than a pack of pimps. Rouge, $n^{\circ} 3,2004$. Disponível em: <http://www.rouge.com.au/3/international.html>. Acesso em 29.02.2020.

LYOTARD, J. F. O acinema. In: RAMOS, F. P. Teoria contemporânea do cinema - Vol. 1. São Paulo: Ed. Senac, 2005.

METZ, C. A significação no cinema. São Paulo: Perspectiva, 2010.

NOGUEZ, D. Éloge du cinéma experimental. Paris: Paris Expérimental, 2010.

O'LEARY, E. Homéo. In: LEBRAT, C; BRENEZ, N. (Orgs). Jeune dure et pure!. Paris: Cinémathèque Française, 2001.

PADELLEC, E. La lumière et l'ombre. Critikat. Paris, 9 out. 2007. Disponível em: <https:// www.critikat.com/panorama/retrospective/pierre-clementi/>. Último acesso em: 29.02.2020.

SHAFTO, S. Zanzibar: Les films Zanzibar et les dandys de Mai 1968. Paris: Paris Expérimental, 2007.

Artigo recebido em 04/03/2020 e aprovado em 22/09/2020. 